\title{
Heat Induced Desorption of Moisture in Timber Joints with Fastener During Charring
}

\author{
Marjan Sedighi Gilani*, Applied Wood Laboratory, EMPA Swiss Federal \\ Laboratories for Materials Science and Technology, 8600 Dübendorf, \\ Switzerland \\ Erich Hugi and Stephan Carl, Building Technology Laboratory, EMPA Swiss \\ Federal Laboratories for Materials Science and Technology, 8600 \\ Dübendorf, Switzerland \\ e-mail: Erich.Hugi@empa.ch \\ Pedro Palma, Institute of Structural Engineering, ETH Swiss Federal Institute \\ of Technology Zürich, Switzerland Wolfgang-Pauli-Str. 15, 8093 Zürich, \\ Switzerland \\ e-mail:palma@ibk.baug.ethz.ch \\ Peter Vontobel, Spallation Neutron Source Division, Paul Scherrer Institute, \\ Villigen, Switzerland \\ e-mail:peter.vontobel@psi.ch
}

Received: 22 October 2013/Accepted: 5 June 2014

\begin{abstract}
Connections are often the weakest link in timber structures so that their failure during fire exposure may result in local or total collapse of a building. The failure modes are complex and poorly understood due to wood's orthotropicity, the temperature and moisture dependency of wood's properties, and the presence of metal fasteners that complicates the stress distribution and changes the process of heat transfer into the timber element. In this study, we investigated the coupled physics of heat and mass transfer in a test specimen made from spruce, with a steel fastener inserted in a pre-drilled hole. It imitates a central slice of a timber-to-timber connection exposed to the elevated temperature of $523 \mathrm{~K}$ from one side. The heat induced redistribution of the hygroscopic moisture in wood was quantified and visualized by means of neutron radiography. The temperature gradient was measured inside the specimen, at different distances from the heated surface. As the temperature increased in wood, moisture was displaced downstream of the heat source, resulting in a zone with increased moisture content ahead of the drying front and beneath the steel fastener. This wet front occurred where the temperature was below the water evaporation point. It was shown that the steel fastener affected the transport of heat and moisture within the test specimen. The occurring phenomena during the transient state may play a critical role in the embedment strength of wood and therefore influence the load-carrying capacity of timber connections in fire.
\end{abstract}

\footnotetext{
* Correspondence should be addressed to: Marjan Sedighi Gilani, E-mail: marjan.gilani@empa.ch
} 
Keywords: Neutron radiography, Fire, Hygroscopic moisture, Moisture displacement, Timber joint

\section{Introduction}

Timber connections play a decisive role in the behavior of timber structures. They are always the weakest link in the structures, especially under fire scenarios, as heat is conducted deep into the wood members by the steel fasteners, which causes faster wood charring [1-3]. Even though the engineering design of timber structures have been advanced significantly during the recent decade, phenomena leading to the failure of wood connections in fire, at both the structural and material levels are not totally understood.

When wood is exposed to fire, a charred layer is built up on the exposed surface, beneath which a zone with a steep temperature gradient makes the transition zone between the advancing char and the inner undamaged wood, (Fig. 1). The rise in temperature leads to drying, shrinkage and thus to the development of micro-cracks in wood that degrade the mechanical properties $[4,5]$. The extent of thermal degradation depends on the incident heat and the exposure time [6]. Thus, the mechanical properties of the transition zone steadily decrease with increasing temperature, until material turns to char with assumed zero strength $[7,8]$.

The load-carrying capacity of timber connections depends, amongst other factors, on the load-bearing behavior of wood under embedment loading of the fasteners. This behavior is in turn highly dependent on moisture and temperature, which both vary when the material is exposed to fire. Variation of moisture content causes dimensional changes (swelling/shrinkage) of the timber and the development of cracks that degrades the mechanical properties and loosens the interaction with fasteners [9]. Thus, decrease of the mechanical properties due to the 'coupled negative effect' of heat and moisture may play a major role on the failure of timber connections with dowel-type fasteners [10-13]. Understanding in detail, the processes leading to failure in timber connections exposed to fire requires studying the physics of transport and the thermo-hygro-mechanical interactions in wood, even though they are not often reflected in engineering design of timber structures for the sake of simplicity.

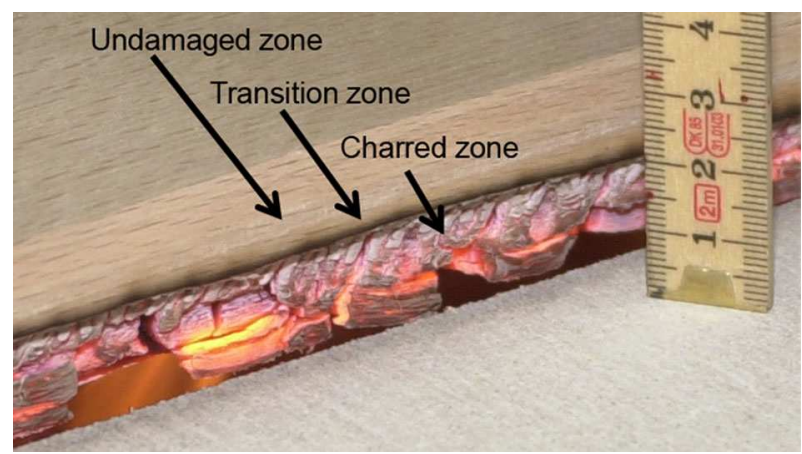

Figure 1. Charred, transition and undamaged wood during fire test. 


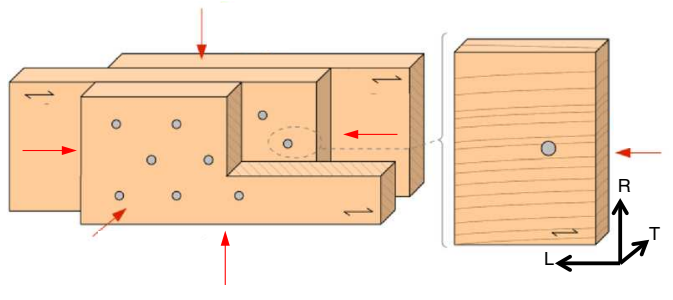

(a)

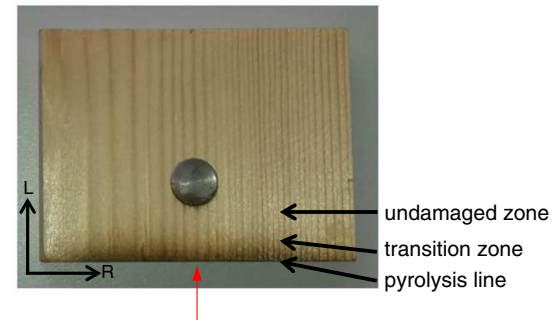

(b)

\section{Figure 2. (a) Geometry of the specimen on right and its location in a connection on left; red arrows show the heat direction, (b) formation of transition zone and initiation of pyrolysis (color change to dark brown) in a test sample (Color figure online).}

Density, permeability, sorptivity, pore size and connectivity are some of the important parameters that influence the transport of heat and mass in a porous media, and are all spatially variable in wood [14]. Another orthotropically variable parameter that is important regarding the transport phenomena in wood is thermal conductivity, which is higher along the grain, compared to the perpendicular to the grain direction, and is tightly linked to moisture [15, 16]. White and Schaffer [17] presented evidence that the hygroscopic water of wood in fire exposed timber slabs migrates from the heating source and accumulates within the slab, with a peak moisture content of 1.25 to 2 times higher than the initial state. Heat induced redistribution of moisture in porous media can be studied with more precision, using recent visualization techniques [18-21]. This includes neutron radiography that, due to the high scattering of the neutrons by hydrogen, makes it possible to visualize and quantify the transport of water vapor in a porous material. Recently, we have used this method to document the heat induced transport of hygroscopic moisture along different orthotropic directions [18, 19]. In this first attempt, the dependency of moisture migration on the geometry of growth rings, for one softwood and one hardwood species was studied. The aim was to study the transport phenomenon in wood as a raw material (without the steel fasteners) and sample surfaces were left exposed to air, resulting in free heat and mass exchange with the air.

In this study, we aimed to investigate the details of transport processes in a wood sample with a steel fastener, as in a dowel-type timber connection exposed to fire (Fig. 2a). Specimens were exposed to temperature of $523 \mathrm{~K}$ from one side, for $40 \mathrm{~min}$, through a surface to surface contact with a heating plate. Heating direction was along the grain. As Fig. $2 b$ shows, for the given moisture content of $12 \%$ and the geometry of sample and contact area, this temperature was sufficient to initiate pyrolysis in the wood (color change to dark brown and crack initiation). Thus, the heating plate imitates the condition of the 'boundary' between the charring and transition zones. Spatial redistribution of hygroscopic water inside the specimen around the fastener was documented by means of neutron radiography while the 
temperature within the specimen was measured by 7 thermocouples. Such study has not been performed up to now, to the knowledge of the authors.

\section{Materials and Methods}

The experiments were performed at the NEUtron Transmission RAdiography (NEUTRA) beamline (http://www.psi.ch/sinq/neutra) of the Paul Scherrer Institute (PSI) in Villigen, Switzerland. This beamline is fed by the Swiss Neutron Spallation Source (SINQ) with neutrons with a thermal spectrum characterized by a Maxwell-like probability density function, with a most probable energy level of about $25 \mathrm{meV}$ [22]. In Fig. 3, the schematic overview of the neutron beamline facility, together with the custom made heating device (inset) is presented. The $\mathrm{x}$ and y-axes correspond to the detector plane axes while the z-axis is the neutron beam direction. The neutron beam meets a detector, which consists of a scintillator- charge-coupled device (CCD) camera system. The scintillator is made of zinc sulfide containing $6 \mathrm{Li}$ as neutron absorbing agent, with a thickness of $100 \mu \mathrm{m}$, converts the neutron signals into visible light photons. The photons are then led via a mirror onto a 16-bit CCD camera $(2048 \times 2048$ pixels $)$. The attained pixel size is on the order of $100 \mu \mathrm{m}$.

The heating device consists of a metallic foil $0.05 \mathrm{~mm}$ thick, placed on the top of a thermally insulating ceramic sheet. Power is provided by a power supply of $50 \mathrm{~A}$ and $120 \mathrm{~V}$. Temperature is measured by two thermocouples, positioned between the foil and the ceramic sheet, using a power supply control algorithm implemented in Labview, to control the heating temperature. Type E thermocouples with diameter

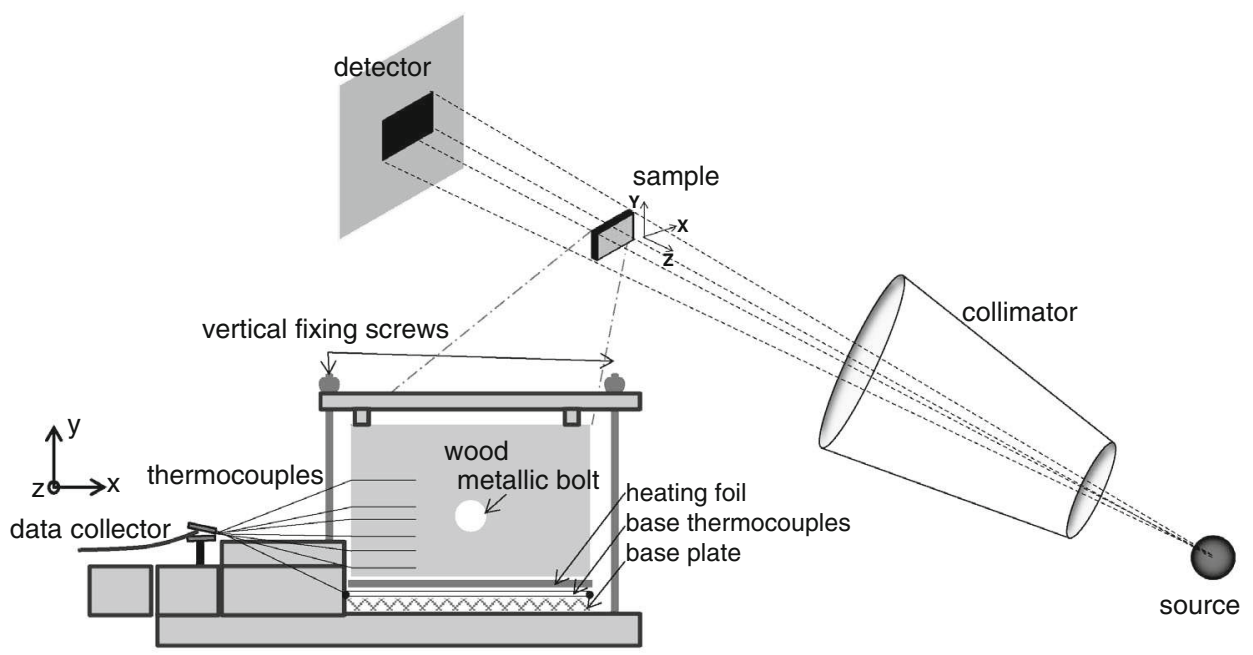

Figure 3. Schematic view of neutron radiography acquisition and heating device setup. 
of $10 \mu \mathrm{m}$ are used to measure the temperature inside the specimens. They were all calibrated in ice/water bath, before the experiments.

We cut 3 replicate specimens from spruce (Picea abies Karst.), in dimensions of 80 (width) $\times 60$ (height $) \times 10$ (thickness) $\mathrm{mm}^{3}$. A steel fastener with a diameter of $12 \mathrm{~mm}$ made from structural steel (grade St 37) was tightly inserted in a pre-drilled hole located $20 \mathrm{~mm}$ from the lower edge of each specimens. Fine drilling machinery was used to precisely drill 7 holes of $0.4 \mathrm{~mm}$ diameter, $20 \mathrm{~mm}$ length and $5 \mathrm{~mm}$ spacing along the height of the specimens, for positioning the thermocouples and measuring the temperature at different distances from the heated surface. The specimens were then conditioned at $20^{\circ} \mathrm{C}$ and $65 \%$ relative humidity (in a desiccator over a saturated $\mathrm{NaNO}_{2}$ salt solution) for 3 weeks, which corresponds to an equilibrium moisture content of $12 \%$. Prior to the experiment, the specimens were weighed and the thermocouples were cautiously inserted into the drilled holes, perpendicular to the heating direction. One additional thermocouple was placed on the surface of the steel fastener, for feedback on temperature of the steel fastener. The specimens were then sealed with a thin Teflon band and insulated with glass foam (10 mm thick) on the lateral surfaces, to impose a one dimensional heat transfer perpendicular to the heated surface, avoiding heat and vapor loss through the lateral surfaces. Therefore, only the top surface remains as an open boundary. Both Teflon and glass foam, containing no high attenuating elements, have minimum interaction with neutrons. Figure 4 show the prepared specimen before the experiment, the raw neutron radiography of the sample before heating and the location of thermocouples in the X-ray radiography of the specimen.

Heating starts with a steep temperature increase from $293 \mathrm{~K}$ up to $523 \mathrm{~K}$ in 2 min that is then maintained during $40 \mathrm{~min}$. Heat flux, considering the comparable thermal diffusivity of the test sample and the base material beneath the heating foil was about $2 \mathrm{~kW} / \mathrm{m}^{2}$. During this period, neutron images are acquired every $17 \mathrm{~s}$, with a spatial resolution of $100 \mu \mathrm{m}$, while temperature inside the specimen is measured with the thermocouples.

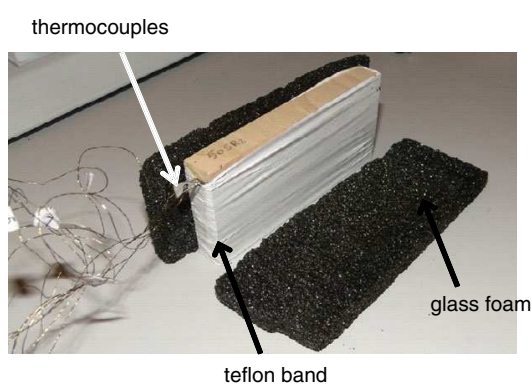

(a)

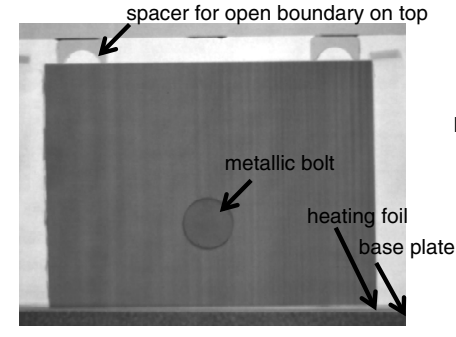

(b)

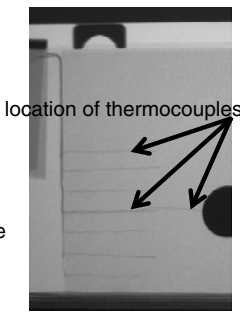

(c)

Figure 4. (a) Specimen before the test, (b) neutron radiography of the specimen, (c) X-ray radiography showing the location of the thermocouples. 


\subsection{Image Analysis}

Neutron radiography is based on intensity measurements of a neutron beam transmitted through an object. The intensity of the transmitted beam, I, can be described with the Beer-Lambert law:

$$
I=I_{0} e^{-\Sigma \cdot z}
$$

where $I_{0}$ is the intensity of the incident neutron beam, $z$ is the total thickness of the object along the beam direction and $\Sigma$ is the neutron linear attenuation coefficient that represents the degree to which a material of a given composition interacts with and attenuates the neutron beam. For a compound material like wood, the effective attenuation coefficient is defined as a function of the attenuation coefficients of the individual elements, including hydrogen, oxygen, carbon, etc. Simplifying the composition of the samples to consist simply of wood and water, we use the bi-layer approximation to quantify the change in the moisture content [23]. With this approximation, the effect of moist wood on neutron attenuation is considered equivalent to the effect of a water layer with thickness $z_{w}$ added to the dry wood sample. Implementing this description, Eq. (1) becomes:

$$
I(t)=I_{0} e^{-\left\{\Sigma_{s} \cdot z_{s}+\Sigma_{w} \cdot z_{w}\right\}}
$$

where the subscript $s$ refers to the wood and $\mathrm{w}$ to the equivalent water layer. At each time $t$ during the experiment, the change in the beam intensity with respect to the initial stage correlates with the change of moisture content, i.e. the change in "effective" water layer thickness in the bi-linear model.

If $z_{w \text {,init }}$ is defined as the thickness of water layer in the initial state, the intensity of the neutron beam transmitted through the sample at the initial state will be:

$$
I_{\text {init }}=I_{0} e^{-\left\{\Sigma_{w} \cdot z_{w, \text { init }}+\Sigma_{s} \cdot z_{s}\right\}}
$$

and Eq. (2) is rewritten as:

$$
I(t)=I_{\text {init }} e^{-\left\{\Sigma_{w} \cdot\left(z_{w}(t)-z_{w, \text { init }}\right)\right\}}=I_{\text {init }} e^{-\left\{\Sigma_{w} \cdot \Delta z_{w}(t)\right\}}
$$

Solving for the change in water thickness yields:

$$
\Delta z_{w}(t)=-\frac{1}{\Sigma_{w}} \ln \left(\frac{I(t)}{I_{\text {init }}}\right)=-\frac{1}{\Sigma_{w}}\left(\ln I(t)-\ln I_{\text {init }}\right)
$$

The change in the moisture content from the initial state (water mass per volume) is obtained by multiplying the change of effective water layer thickness, $\Delta z_{w}(t)$ by the water density, $\rho \mathrm{w}$ and dividing by the sample thickness, $z_{s}$. It allows plotting differential moisture content (water mass per volume, $\mathrm{kg} / \mathrm{m}^{3}$ ) at different times. 


$$
\Delta w(t)=w(t)-w_{\text {init }}=-\frac{\rho_{w}}{z_{s} \cdot \Sigma_{w}}\left(\ln I(t)-\ln I_{\text {init }}\right)
$$

In order to correct for some of the artifacts produced by the experimental configuration, each raw neutron radiograph has to be pre-processed, based on methods for radiation transmission-based imaging [24]. This includes correction for background noise of the CCD camera, for spatial fluctuations of the incident beam, for scattering by the experimental configuration and environment, and polychromaticity of beam energy spectrum. The Quantitative Neutron Imaging (QNI) algorithm, developed at Paul Scherrer Institute was used for this purpose [24]. Quantitative study, based on uncorrected radiographs, would result in an underestimation of the water content, up to $50 \%$, compared with corrected radiographs [25].

\section{Results and Discussions}

\subsection{Time-resolved migration and desorption of moisture}

In Fig. 5, the total change of moisture content (from the initial state), derived based on Eq. 6, for 3 replicate specimens has been shown. Each circular marker corresponds to the quantified moisture content from a neutron radiography image. The initial moisture content of the specimens, measured by gravimetry was around $41 \mathrm{~kg} / \mathrm{m}^{3}$. The total mass loss at the end of the experiment has been determined by both neutron radiography and precision balance and corresponds within $10 \%$, validating the procedure for quantifying the moisture content from the neutron images. Results of the replication experiments were comparable, though some differences, attributed to the natural heterogeneity in wood, e.g. different permeability, and also imperfection in providing adiabatic boundary condition were observed. In the first few minutes, shown by vertical arrows for each sample, the slope of the curves was less varying, but decreased more significantly after $5 \mathrm{~min}$ heating. This shows that moisture did not leave the specimen in the first few minutes, e.g., 5 min in sample_A, but redistributed due to the heat exposure until the drying started to take place afterward. The drying rate increased with exposure time, thus moisture desorption faced less resistance in a prolonged heat exposure. For example in sample_A, the initial moisture content of $41.5 \mathrm{~kg} / \mathrm{m}^{3}$ was reduced to $40.5 \mathrm{~kg} / \mathrm{m}^{3}$ after $15 \mathrm{~min}$ and to $36.5 \mathrm{~kg} / \mathrm{m}^{3}$ after $40 \mathrm{~min}$.

Neutron images were analyzed in more detail, for discussing the 'spatial' and 'temporal' redistribution of moisture during the heat exposure. Figure 6 shows the profiles (on left) and plots (on right) of the variation of moisture content 'from the initial state', after 3, 5, 15, 25 and 40 min from the beginning of heat exposure on the lower surface of the sample_A. The moisture profiles have been obtained along two indicated vertical cross sections with dashed lines, one in the middle and the other off center. A few minutes after beginning of the experiment, a drying zone developed close to the heat source that progressed upwards with the time of exposure. The migrated moisture accumulated above this drying front, as is known for the heat induced process of moisture transport in wood [18, 19]. Wood 


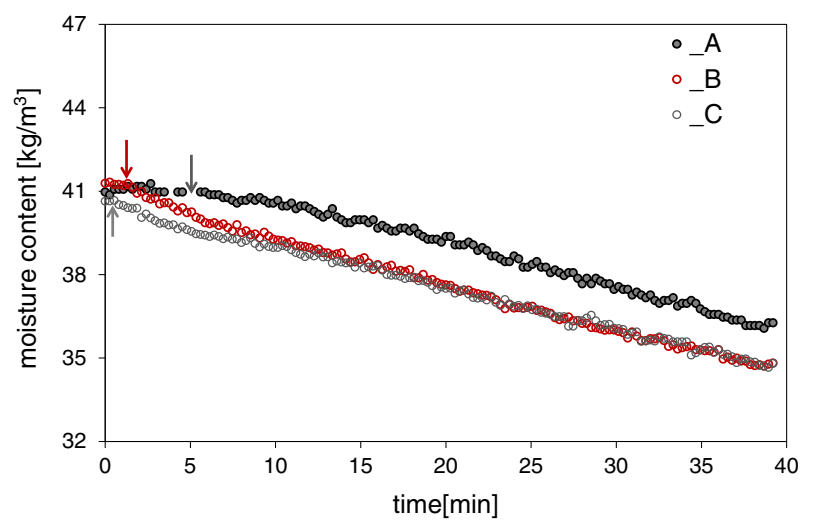

\section{Figure 5. Desorption of moisture in 3 tested samples during $40 \mathrm{~min}$ single edge heating at $523 \mathrm{~K}$.}

structure, mainly the grain orientation influenced the pattern of mass transfer, i.e. the observed jagged pattern is due to the growth rings. Different drying rates in seasonal growth rings are due to differences in density, and thus in the transport properties, which can be related to the presence of larger fiber lumens in earlywood compared to latewood layers. The progression of the drying/wetting zones is almost horizontal, as a result of implementing the adiabatic and vapor tight boundaries around the specimen. However, providing an ideal adiabatic and vapor tight boundaries in practice was not feasible. Thus some drying patterns towards the sides of the sample were observed that indicated the slight presence of heat convection and evaporation of moisture at those surfaces. Thermocouples, due to their very small diameter, had no important influence on the transport process.

When the moisture front reached the steel fastener, due to the vapor impermeability of steel, the transport process was altered. Moisture started to accumulate significantly (up to $150 \mathrm{~kg} / \mathrm{m}^{3}$ ) beneath the lower surface of the fastener, shown by horizontal black arrows, while moisture accumulation in the areas away from the fastener advanced with a different magnitude and speed. Given the density of tested spruce was about $410 \mathrm{~kg} / \mathrm{m}^{3}$, accumulated moisture content in mass [\%] is $36 \%$, which is apparently higher than the measured peak moisture content in wood without fastener [17] and the fiber saturation point. Afterward, the moisture front advanced toward the downstream of the heat source, though the influence of the steel fastener on the pattern of moisture redistribution in the center and in the sides of the fastener was observed until the end of the experiment. A hastened drying (yellow color) was observed above the steel fastener, only after 5 min heating, when the shown moisture accumulation zone by horizontal gray arrows was still advancing upward from the sides of the fastener. This early drying, close to the fastener, could potentially result in initiation of shrinkage cracks and loosening the interaction between the wood and the fastener. Also, the substantial increase of the moisture content beneath the fastener results in decrease of the wood stiffness and embedment strength. 

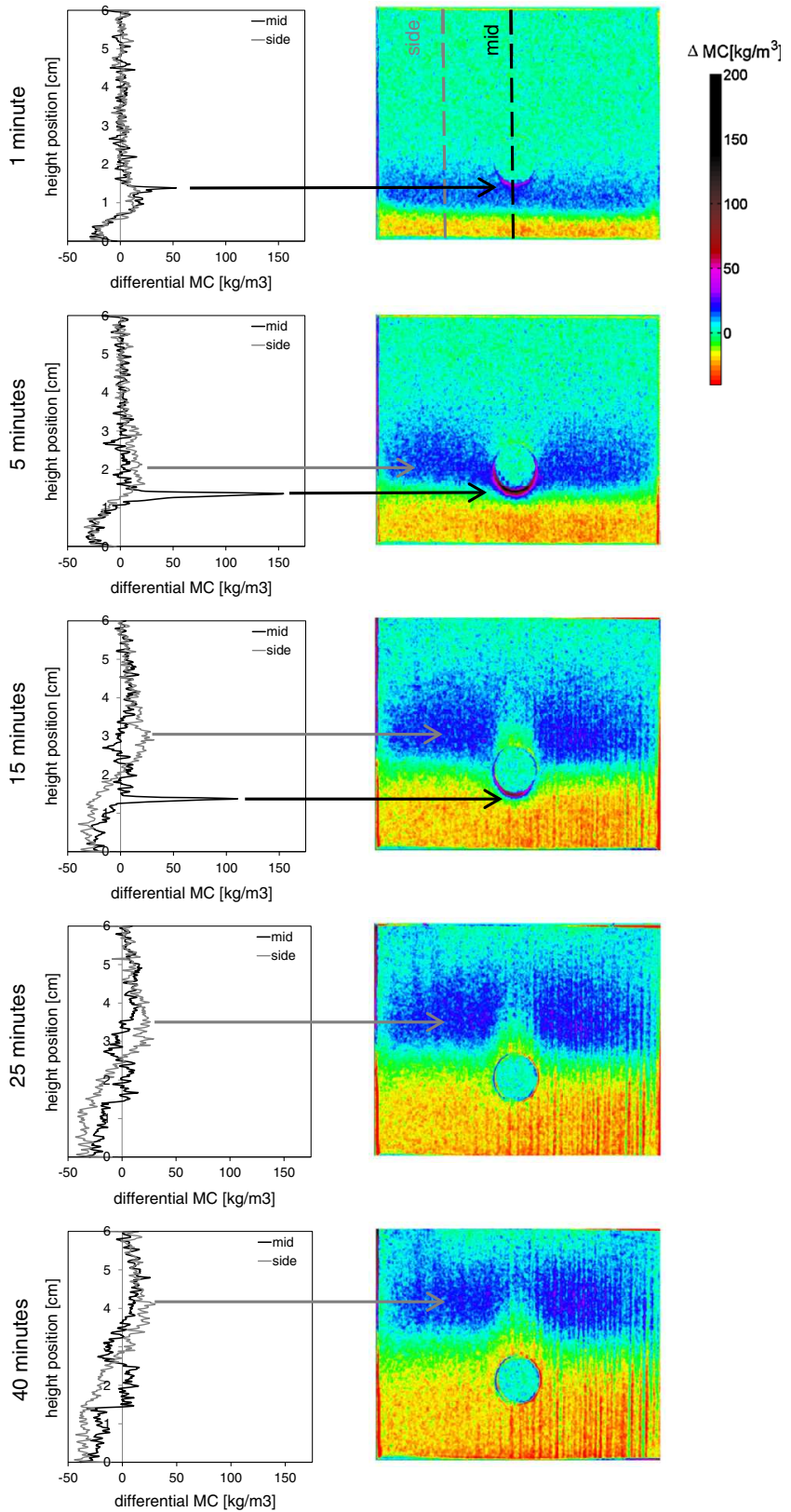

Figure 6. Profiles (on left) and plots (on right) of the differential moisture content in the specimen_A, obtained from neutron radiography, after 3, 5, 15, 25 and $40 \mathrm{~min}$ heat exposure. 


\subsection{Temporal Change of Temperature}

The time resolved temperatures measured at the tip of thermocouples $(5,10,15$, 20, 25, 30 and $35 \mathrm{~mm}$ from the base) are plotted in Fig. 7. The measured temperature at the center of steel fastener is presented as a thick dashed line, which was close to the temperature in wood at similar height position $[20 \mathrm{~mm}]$.

Neutron beam did not affect the thermocouples, measuring the temperature with time interval of $30 \mathrm{~s}$ until the end of experiments. Temperature increase occurred with a high rate in the first $5 \mathrm{~min}$. The plateau that appeared right after the sharp increase of the temperature in the first few minutes showed the time and temperature at which the hygroscopic moisture and the condensate water beneath the fastener were changing phase (latent heat). Intersection of the water evaporation temperature, with the measured temperature at $15 \mathrm{~mm}$ height position is shown with thin dashed lines. This location is near the lower side of the steel fastener, where the maximum moisture accumulation occurred between $5 \mathrm{~min}$ and $15 \mathrm{~min}$. Analyzing the figure closer shows that at $5 \mathrm{~min}$, when moisture accumulation at this location was the maximum, temperature was $363 \mathrm{~K}\left(90^{\circ} \mathrm{C}\right)$ and stayed below the water evaporation point until $8.7 \mathrm{~min}$. The lower measured temperature than evaporation point, at the time the moisture front passes the position of the thermocouples was in agreement with the literature [13, 18, 19]. Note that in the absence of experimental data about the gas pressure, verifying the water phase in this high temperature moisture accumulation zone, beneath the steal fastener, is not possible. Also, neutron radiography is not capable of differentiating between the hygroscopic, liquid and vapor water.

Due to all these uncertainties, understanding the detailed physics of heat and induced mass transport in timber joints is still a complex problem. In practical structural engineering, the role played by the wood hygroscopic water on its physico-mechanical interactions, especially in a fire scenario, is often passed over.

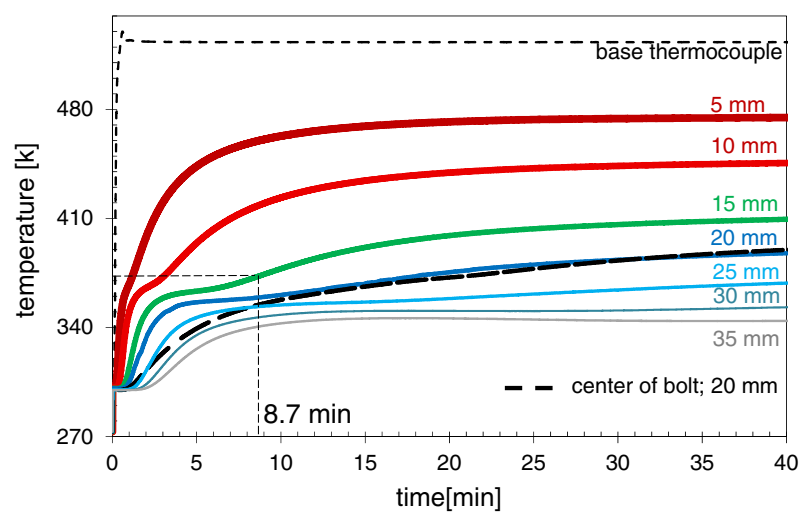

Figure 7. Measured temperature at the tip of thermocouples on the heating foil (base thermocouples), 7 measuring points placed every $5 \mathrm{~mm}$ from the heated surface and on the surface of the steel fastener in the specimen_A. 
However, wood mechanical properties are known to be not only dependent in type, orientation and duration of load in the connections, but also in moisture and temperature that both change rapidly inside timber elements when a structure is subjected to fire. The coupled interaction of heat and the induced mass transport in a complex structural element from wood and metallic fastener may cause critical transient condition, i.e., reduced mechanical properties due to heat, wetting and shrinkage cracks, to take place during a fire scenario. These negative effects can cause structural failure even at temperatures below the charring temperature, so explain the need for an in-depth study of the involved phenomena in triggering the failure of timber connections in fire at 'material' scale.

Finally we should address the limitations of the present experimental study. Due to the specific geometry, size and boundary conditions of the specimens, it is difficult to analyze and quantify the 'real' ongoing processes in timber joints during fire exposure. In terms of geometry, considering samples of larger thickness would have been more relevant. However, dimensions of the samples are dictated by neutron radiography setup, e.g., limited thickness to few $\mathrm{mm}$ [26] for accuracy of moisture content quantification. However, we tried to overcome this inadequacy by considering adiabatic and vapor tight conditions at the sides of the specimens. Despite the limitations, the results provide new insight about the role played by the hygroscopic moisture of wood and its redistribution when a timber connection is exposed to fire, and draw attention to the possibility of the initiation of timber connections failure at material/microstructural level.

\section{Conclusion}

Connections, often showing a resistance lower that provided by other structural elements, govern the load-carrying capacity of the whole timber structure in fire. Neutron radiography, together with measurement of temperature in a wood and steel fastener specimen, in controlled single edge heating experiments were used to study the heat and induced mass transport and resultant hygro-thermal processes in timber connections during the fire exposure. Specimens, representing a central member of timber-to-timber connection, were exposed to elevated temperature of $523 \mathrm{~K}$ on one edge. Due to the evident initiation of wood pyrolysis in the heat exposed edge, the configuration imitates the boundary between the charring and transition zones in fire exposure. Migration and evaporation of the hygroscopic moisture in wood were analyzed by the contrast in the scattering of thermal neutrons, during $40 \mathrm{~min}$ of heat exposure.

In this pilot study, neutron radiography analysis showed that, in a timber connection exposed to fire, along the grain transport of moisture is non-uniform. Moisture migrates irregularly in a jagged pattern caused by geometry of the growth rings (difference of vapor permeability of earlywood and latewood) and is locally affected by the geometry of the steel fasteners. Heat and the induced moisture accumulation degrade the wood mechanical properties beneath the fasteners while drying and shrinkage cracking may occur on the other side. The resulting moisture accumulation coincides with the measured temperature below $363 \mathrm{~K}\left(90^{\circ} \mathrm{C}\right)$. 
These changes influence the wood-steel contact interactions and weaken the embedment strength of wood and the load-carrying capacity of the connection. Further studying the process of moisture transport and temperature distribution, in relation to the geometry of the connection and grain orientation is required to establish the link between the hygro-thermo-mechanical behavior of wood around the fasteners and the structural behavior of timber connections exposed to fire. Such information can then be implemented in a coupled thermo-hygro-mechanical model of timber connections to predict their fire behavior.

\section{Acknowledgement}

The experiments were carried out at the NEUTRA beamline of the Paul Scherrer Institute and EMPA Laboratories for Materials Science and Technology, Switzerland. The authors would like to acknowledge the support of Daniel Heer from EMPA for sample preparation and of Jan Hovind from Paul Scherrer Institute NEUTRA beamline for maintenance of neutron imaging soft- and hard-ware.

\section{References}

1. Madsen B (2000) Behavior of timber connections. Timber Engineering Ltd, Canada

2. Peng L, Hadjisophocleous G (2011) Predicting the fire resistance of wood-steel-wood timber connections. Fire Technol 47:392-399

3. Maraveas C, Miamis K, Matthaiou CE, Maraveas C (2013) Performance of timber connections exposed to fire: a review. Fire Technol . doi:10.1007/s10694-013-0369-y

4. Chen G, Keey RB, Walker JCF (1997) The drying stress and check development on high temperature kiln seasoning of sapwood Pinus radiata boards. Holz als Roh-und Werkstoff 55:59-64

5. Sedighi-Gilani M, Boon M, Fife J, Ghazi Wakil K (2013) Dynamic of micro-cracks initiation in hardwood in pyrolysis, investigated by synchrotron X-ray tomography. Wood Sci Technol 47:889-896

6. Ostman B (1985) Wood tensile strength at temperatures and moisture contents simulating fire conditions. Wood Sci Technol 19:103-116

7. Moraes P, Rogaume Y, Boequet JF, Triboulot P (2005) Influence of temperature on the embedding strength. Holz als Roh-und Wekstoff 63:297-302

8. Young S, Clancy P (2001) Compression mechanical properties of wood at temperatures simulating fire conditions. Fire Mater 25:83-93

9. Malanga R (1995) Fire endurance of lightweight wood trusses in building construction. Fire Technol 31:44-61

10. Lenth C, Sargent R (2008) Wood material behavior during drying: moisture-dependent tensile stiffness and strength of radiata pine at $70-150^{\circ} \mathrm{C}$. Drying Technol $26: 1112-1117$

11. Pearson H (2010) Material properties and stress modeling of radiata pine at high temperature. PhD Thesis, University of Waikato, Hamilton

12. Pearson H, Gabbitas B, Ormarsson BS (2012) Tensile behaviour of radiata pine with different moisture contents at elevated temperatures. Holzforschung 66:659-665

13. Reszka P (2008) In-depth temperature profiles in pyrolyzing wood. PhD dissertation, University of Edinburgh, Scotland 
14. Siau J (1984) Transport process in wood. Springer-Verlag, New York

15. Leon G, Cruz-de-Leon J, Villasenor L (2000) Thermal characterization of pine wood by photoacoustic and photothermal techniques. Holz Roh-und Werkstoff 58:241-246

16. Sonderegger W, Hering S, Niemz P (2011) Thermal behaviour of Norway spruce and European beech in and between the principal anatomical directions. Holzforschung 65:369-375

17. White RH, Schaffer EL (1981) Transient moisture gradient in fire-exposed wood slab. Wood Fiber Sci 13(1):17-38

18. Sedighi-Gilani M, Vontobel P, Lehmann E, Derome D, Carmeliet J (2013) Moisture migration in wood under heating by thermal neutron radiography. Exp Heat Transfer 27(2):160-179

19. Sedighi-Gilani M, Abbasion S, Lehmann E, Carmeliet J, Derome D (2014) Neutron imaging of moisture displacement due to steep temperature gradients in hardwood. Int J Thermal Sci 81:1-12

20. van der Heijden G, Huinink HP, Pel L, Kopinga K (2011) One-dimensional scanning of moisture in heated porous building materials with NMR. J Magn Reson 208(2):235242

21. Gilani S, Ghazi Wakili K, Carl S, Hugi E, Vontobel P (2013) Visualizing moisture release and migration during and beyond dehydration of gypsum plasterboard by neutron radiography. Int J Heat Mass Transfer 60:284-290

22. Lehmann E, Vontobel P, Wiezel L (2001) Properties of the radiography facility NEUTRA at SINQ and its potential for use as European reference facility. Nondestruct Test Evaluat 16:191-202

23. Sedighi-Gilani M, Grifa M, Mannes D, Lehmann E, Carmeliet J, Derome D (2012) Visualization and quantification of liquid water transport in softwood by means of neutron radiography. Int J Heat Mass Transfer 55(21-22):6211-6221

24. Hassanein R (2006) Correction methods for the quantitative evaluation of thermal neutron tomography. PhD thesis, ETH Zurich, Switzerland

25. Hassanein R, Meyer HO, Carminati A, Estermann M, Lehmann E, Vontobel P (2006) Investigation of water imbibition in porous stone by thermal neutron radiography. $\mathrm{J}$ Phys D Appl Phys 39(19):4284-4291

26. Hassanein R, Lehmann E, Vontobel P (2005) Methods of scattering corrections for quantitative neutron radiography. Nucl Instrum Methods A 542:353-360 